\title{
LESS Cholecystectomy Using Conventional Instruments Combined with the Clip-Less Technique
}

\author{
Ashwin Rajendiran ${ }^{1}$, Poobalou Rajendiran ${ }^{1}$, Kathiresan Karunakaran², Palanisamy Jayakumar ${ }^{2}$ \\ ${ }^{1}$ Department of Minimal Access Surgery, Madhava Hospital, Nellithope, Pondicherry - 605005; ${ }^{2}$ Department of General Surgery, \\ Sivagangai Medical College, Sivagangai, Tamilnadu - 630561, India.
}

\section{Corresponding Author: \\ Dr. Ashwin Rajendiran \\ Email: ashwin90ster@gmail.com}

This is an Open Access article distributed under the terms of the Creative Commons Attribution License (creativecommons.org/ licenses/by/3.0).

$\begin{array}{lll}\text { Received } & : & \text { October 14, 2017 } \\ \text { Accepted } & : & \text { January 27, } 2018 \\ \text { Published } & : & \text { June 25, 2018 }\end{array}$

\begin{abstract}
Background: Laparo-endoscopic single site cholecystectomy (LESS) has gained popularity as a cosmetically better procedure than conventional laparoscopic cholecystectomy. We hereby report our initial experience of 52 cases of LESS cholecystectomy. Materials and Methods: We used a 15-20 mm incision at umbilicus, 2 ports and conventional laparoscopic instruments with occasional use of additional ports $(3 \mathrm{~mm})$ and the puppeteer technique for gall bladder retraction using stay sutures. Harmonic scalpel was used for dissecting and dividing the cystic duct (clipless technique) in most of cases $(n=42)$, exceptions being the initial few cases and wider cystic ducts. We were able to achieve Strasburg's critical view of safety in all the cases. Results: Out of 52 cases, 18 were of acute cholecystitis and the rest were elective cholecystectomies. Complications (tearing of stay sutures, hemorrhage) in our series were managed comfortably and none of the cases needed conversion to conventional laparoscopic cholecystectomy. The mean operating time was 60 minutes for the initial ten cases whereas it was as short as 12 minutes, in an elective cholecystectomy. Average blood loss was $16.5 \mathrm{ml}$. Post-operative umbilical seroma was noted in initial 5 cases. The patients were followed up for a period of six months and none of them developed port site hernia. Conclusion: In our experience, LESS cholecystectomy using harmonic scalpel is feasible and advantageous in certain aspects. Though loss of triangulation and clashing of instruments are unavoidable, in the hands of a trained laparoscopic surgeon, the learning curve is quite short and results are promising.
\end{abstract}

Keywords: Cholecystitis, Cystic Duct, Laparoscopic Cholecystectomy, Laparoscopy.

\section{Introduction}

Laparoscopic cholecystectomy (LC) is currently the procedure of choice for surgical removal of the gall bladder. Single incision laparoscopic surgery (SILS) is a major milestone in the journey towards minimizing scar in laparoscopy. The major setbacks in SILS include increased incidence of postoperative complications like umbilical seroma, port site hernia and increased cost [1].

With the quest to devise a better alternative to SILS, that is both cost effective, cosmetically better and has a fairly short learning curve, many techniques of single-site access cholecystectomy have been reported and they are referred as laparoendoscopic single site surgery (LESS) [2]. We hereby report our initial, single surgeon experience with 52 cases in LESS cholecystectomy with clip-less technique using a 10-15 mm incision at umbilicus, 2 ports $(5 \mathrm{~mm}$ with another 5 or $10 \mathrm{~mm}$ ) and conventional straight laparoscopic instruments with the occasional use additional ports $(3 \mathrm{~mm})$. 


\section{Methodology}

We performed LESS cholecystectomy in 52 patients over a span of 18 months. A brief clinical summary was noted along with the anthropometry. Intra-operatively, the gall bladder was assessed for predictors of difficult LC using a proforma. Operative parameters like duration of surgery, blood loss, complications and conversion rate to multiport LC were recorded. The surgical team for LESS cholecystectomy comprised of an operating surgeon, a camera assistant and an assistant at the retraction site. The patients were operated under general anesthesia with the help of standard laparoscopy instruments and HarmonicTM scalpel. They were placed in French position. The surgeon faced the pelvis of the patient and the assistant was placed in the right side.

A $15-20 \mathrm{~mm}$ vertical incision was made through the umbilicus and the subcutaneous layer was separated. A $10 \mathrm{~mm}$ port was inserted at upper end of the incision after Verres' insufflation. A second $5 \mathrm{~mm}$ working port was inserted at the lower end of the incision. The fascial entries of the two ports were directed away from each other to prevent clashing of instruments. We used a

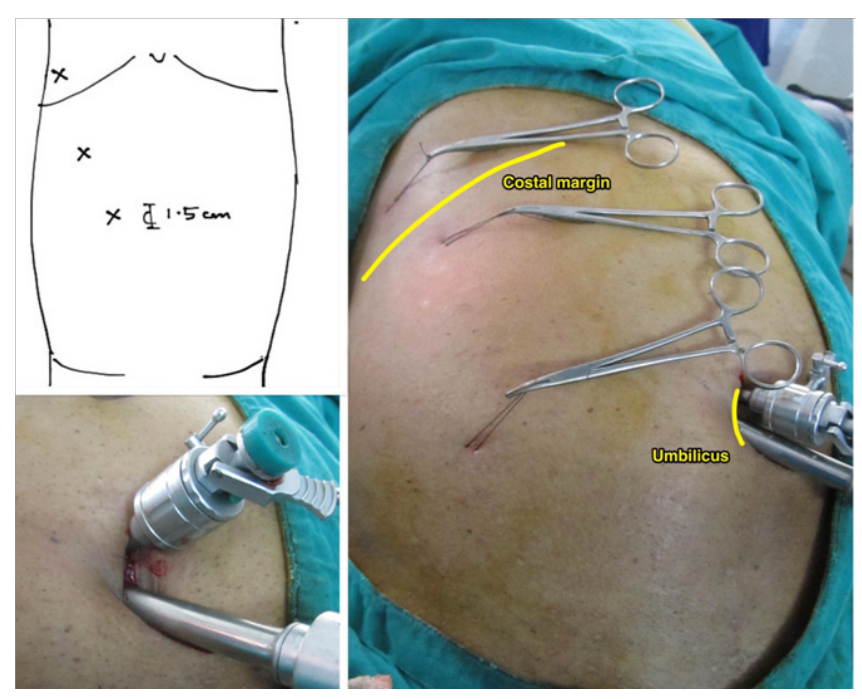

Fig.1: Incision, placement of trocars and site of application of the stay sutures. Note that the trocar heads are placed at different levels to avoid clashing.
$5 \mathrm{~mm}$ and a $10 \mathrm{~mm}$ trocar initially but changed over to two $5 \mathrm{~mm}$ trocars making use of a $5 \mathrm{~mm}$ telescope for better ergonomics. Furthermore, one of the $5 \mathrm{~mm}$ trocars was replaced with a valveless trocar to avoid clashing of the two trocar-heads [Fig.1]. A general assessment of the peritoneal cavity was done. Parameters observed were gall bladder visibility, discolouration, contraction/ distension, inflammation, overhanging liver edge and adhesions over the gall bladder.

Gall bladder was retracted using the puppeteer technique with sutures passed serially into the peritoneal cavity. The first suture was passed through the $10^{\text {th }}$ intercostal space along the mid-axillary line and taken at the fundus of gall bladder. The second suture was passed at a point midway between the xiphisternum and umbilicus at the anterior axillary line and taken at the body of gall bladder that is closest to the neck. If the Callot's triangle was not displayed with two stay sutures, a third suture was passed near the umbilicus along the mid-clavicular line and taken at the Hartmann's pouch. The first retraction is predominantly upward whereas the second and third tend to retract the GB downward and laterally. Compared to retraction in conventional laparoscopic cholecystectomy (CLC), the structures at Callot's triangle are sometimes rotated after suture retraction and the third stay bite described above is helpful in counteracting this torsion. A clamp applied flush to the skin surface retains the retraction at that site [Fig.1,2]. In cases

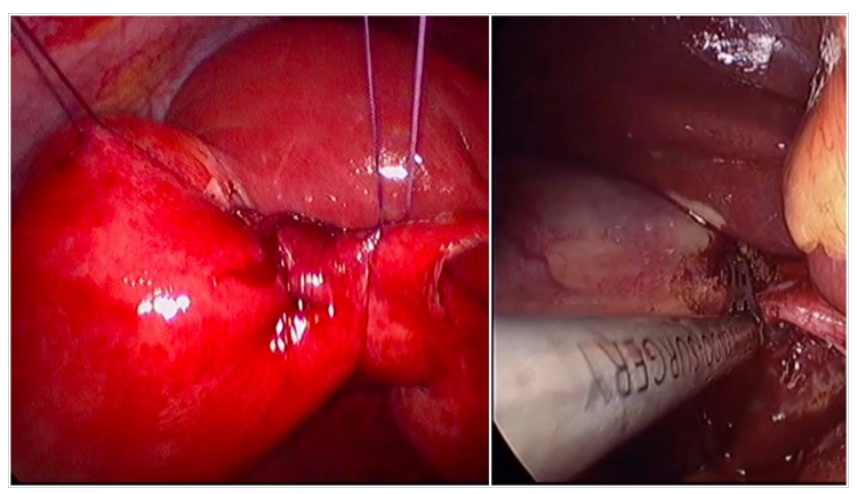

Fig.2: Suspension of the gall bladder with serial stay sutures and dividing the cystic duct with harmonic scalpel. 
of overhanging liver edge, we used a $2 \mathrm{~mm}$ port at the right hypochondrium to lift the liver edge. It is to note that the exact point of entry is many-a-times tailor made considering the built of the patient and the nature of gall bladder as assessed above.

The following techniques helped quick but effective application of stay retractions: (a) the needle was flattened proximally prior to piercing the abdominal wall. A straight needle would be easier to pierce but has a higher chance of lateral injury while taking the bite at the gall bladder; (b) broad bite was taken involving the full thickness of the gall bladder wall to avoid tearing of the stay sutures (c) entry and exit sites of stay sutures on the skin were kept as close as possible to prevent Gigli's saw effect thereby causing fundus tear. Dissection of Calot's triangle was carried out in usual manner. We used harmonic ${ }^{\mathrm{TM}}$ forceps for dissection. In addition to a better hemostasis, this curtailed repeated instrument passage and change of camera position, thus shortening the operating time. Strasberg's critical view of safety was achieved in all the cases and the retraction at Hartmann's pouch was very useful with respect to the same. We used the clipless technique using harmonic $^{\mathrm{TM}}$ forceps for dividing the cystic duct. The cystic duct, if found to be larger, was divided in between clips or hemlocks.

Once the gall bladder was dissected out from its bed, the stay sutures were pulled out. The two fascial entry points were combined and the gall bladder comfortably retrieved without spillage. Port closure was done using extra-corporeal technique by direct visualization of the fascia. Skin was closed with sub-cuticular sutures.

\section{Results}

The anthropometric details of our patients who underwent laparoscopic cholecystecomy are presented in Table 1. Mean age at presentation was 42.1 years. Mean pre-operative BMI was 25.2. Out of 52 cases, 18 presented with acute episode of cholecystitis. The rest were elective cholecystectomies.

The operative details are described in Table 2. One $5 \mathrm{~mm}$ and $10 \mathrm{~mm}$ ports were used in most of the cases. Ancillary ports were required in 7 cases, where a $3 \mathrm{~mm}$ grasper or liver retractor was used at epigastric or hypochondrial region. Stay sutures were taken over the gall bladder at 2 or 3 sites for retraction. The mean operating time was 60 minutes for the initial ten cases whereas it was as short as 12 minutes, in a case of elective cholecystectomy. Metallic clips were applied initially before switching over to clipless cholecystectomy and in occasional cases of large

Table 1: Pre-operative parameters.

\begin{tabular}{|l|l|}
\hline Mean age of presentation (years) & 42.1 \\
\hline Mean pre- operative BMI & 25.2 \\
\hline Highest pre-operative BMI & 38.8 \\
\hline Indications for cholecystectomy & \\
- Acute cholecystitis & $18(34.6 \%)$ \\
- Mucocele of gall bladder & 2 \\
- Cholelithiasis & 32 \\
\hline
\end{tabular}

Table 2: Intra-operative and post operative parameters

\begin{tabular}{|l|l|}
\hline Operating time (min) & 46 \\
\hline $\begin{array}{l}\text { Ports } \\
\text { - } 10 \mathrm{~mm}+5 \mathrm{~mm}\end{array}$ & 48 \\
- additional ports & $7(13.4 \%)$ \\
\hline Adhesions (moderate to severe) & 3 \\
\hline Blood loss (ml) & 16.5 \\
\hline $\begin{array}{l}\text { Cystic duct ligation } \\
\text { - Harmonic }\end{array}$ & \\
- Clip/ Hemolock & \\
\hline Complications & $42(72.7 \%)$ \\
- Tearing of stay sutures & $10(27.2 \%)$ \\
- Hemorrhage (cystic artery injury) & 1 \\
- Drain requirement & $5(9.6 \%)$ \\
- Conversion rate & 1 \\
- Post op umbilical discharge & Nil \\
- Port site hernia & $5(9.6 \%)$ \\
\hline
\end{tabular}


cystic duct $(n=10)$. Hemolock ${ }^{\mathrm{TM}}$ was used in two cases with dilated cystic-duct.

Tearing of stay sutures at the gall bladder fundus was encountered in 5 cases. Gall bladder spillage was suctioned and sutures were taken again. Hemorrhage due to inadvertent cystic artery injury was seen in a single case. It was effectively controlled with compression after removing the stay sutures. Thus the conversion rate to multiport LC was nil. Post-operative serous discharge was noted at the umbilicus in 5 cases. All the patients were followed up for a period of six months and none of the patients developed port site hernia.

\section{Discussion}

The journey towards a completely scarless surgery took a major leap when laparoscopy took over open surgery as the standard of care for cholecystectomy. But nevertheless, the quest for a better cosmetic outcome continued. Traditional four port laparoscopic surgeries were started being performed by passing multiple instruments through a single umbilical site through a specialized port device. This was the advent of SILS. As umbilicus was a natural scar by itself, the SILS was compared to a scarless surgery.

But SILS had its own setbacks. First and foremost, the armamentarium of SILS required specially angulated instruments and the port device, which added up to the cost of the surgery. Also, the same contributed to a longer learning curve. Since the umbilical incision is larger, it increases the risk of port site hernias. The pressure of the device at the umbilicus also contributed to increased post-operative pain compared to conventional laparoscopy.

LESS technique evolved as a fair alternative to SILS with comparable cosmetic outcome at a significantly reduced cost. As newer techniques are being reported, a plethora of terminologies have surfaced leading to technical jargon. These names like SILS-single-incision laparoscopic surgery;
OPUS-one-port umbilical surgery; SIMPLEsingle-incision multi-port laparo-endoscopic surgery; so on, apart from displaying the surgeons' creativity, only complicate standardization of these procedures for documentation and research. The LESSCAR (Laparo-endoscopic single site surgery consortium for assessment and research) convention has suggested the name of LESS surgery for all such procedures, which used a single site for access. The consortium also suggested a standardization for reporting these surgeries as follow including the length and location of incision, approach, number/type of ports used, type of instruments used and whether any ancillary 2-mm needlescopic instrumentation or extra ports employed [3].

Our technique of LESS cholecystectomy is not only feasible but also advantageous in certain aspects. The incision used in our technique is a trans-umbilical incision, smaller than the one used for SILS. Also any incision placed in the normal skin outside the umbilicus has a variable outcome making this incision superior to the incisions described in other methods of reduced port cholecystectomy [4]. As the incision is larger than $1 \mathrm{~cm}$, the rectus sheath can be better visualized while port closure. The stay sutures in this technique give a constant steady traction from outside and have a mechanical advantage over conventional fundus retraction which is applied from inside the abdominal cavity. Also, the surgeon has the liberty to apply additional stay retractions in difficult cases. We have used a maximum of five stay sutures in a case of acute cholecystitis. We encountered complications like tearing of stay sutures and hemorrhage in the initial cases and further down the lane, as we refined our technique, the complication rate significantly reduced.

Certain constraints of LESS cholecystectomy cannot be ignored. They include sword fighting of the instruments and loss of triangulation. The former can be minimized by 
placing the trocar heads at different levels to each other. Loss of triangulation is inevitable in LESS cholecystectomy. Certain authors have tried crossing the instruments similar to a chop stick and achieving a cross triangulation. With our technique, we were able to demonstrate the Callot's triangle without any compromise and the loss of triangulation was not a hitch. Also, with familiar instruments, LESS technique has a fairly short learning curve. This technique can thus be effectively used in place of conventional LC and is advantageous in terms of cosmetic outcome $[5,6]$. Some studies claim decreased post-operative pain in LESS cholecystectomy compared with CLC whereas the complications and hernia risk remain the same $[7,8]$.

\section{Conclusion}

Technical reports of single site cholecystectomy reported so far have mostly used three ports with or without the puppetry technique. We conclude that two port single site LESS cholecystectomy using harmonic forceps for dissection and dividing the cystic duct can be effectively performed with a shorter learning curve and no additional morbidity.

Contributors: AR: manuscript writing, patient management; PR: manuscript editing, patient management; KK, PJ: critical inputs to the manuscript. AR will act as guarantor. All authors approved the final version of this manuscript.

Funding: None; Competing interests: None stated.

\section{References}

1. Fransen S, Stassen L, Bouvy N. Single incision laparoscopic cholecystectomy: A review on the complications. J Minimal Access Surg. 2012;8:1-5.

2. Bucher P, Ostermann S, Pugin F, Morel P. Female population perception of conventional laparoscopy, transumbilical LESS, and transvaginal NOTES for cholecystectomy. Surg Endosc. 2011;25:2308-2315.

3. Rao PP, Rao PP, Bhagwat S. Single-incision laparoscopic surgery - current status and controversies. J Minimal Access Surg. 2011;7:6-16.

4. Hodgett SE, Hernandez JM, Morton CA, Ross SB, Albrink M, Rosemurgy AS. Laparoendoscopic single site (LESS) cholecystectomy. J Gastrointest Surg Off J Soc Surg Aliment Tract. 2009;13:188-192.

5. Sinha R. Transumbilical single-incision laparoscopic cholecystectomy with conventional instruments and ports: the way forward? J Laparoendosc Adv Surg Tech A. 2011;21:497-503.

6. Hernandez J, Ross S, Morton C, McFarlin K, Dahal S, Golkar F, et al. The learning curve of laparoendoscopic single-site (LESS) cholecystectomy: definable, short, and safe. J Am Coll Surg. 2010;211:652-657.

7. Antoniou SA, Pointner R, Granderath FA. Singleincision laparoscopic cholecystectomy: a systematic review. Surg Endosc. 2011;25:367-377.

8. Madureira FAV, Manso JEF, MadureiraFo D, Iglesias ACG. Randomized clinical study for assessment of incision characteristics and pain associated with LESS versus laparoscopic cholecystectomy. Surg Endosc. 2013;27:1009-1015. 